Supporting Information for

\title{
Polyanion Substitution in Polyelectrolyte Complex Dispersions Studied by Spin-Label EPR Spectroscopy
}

Uwe Lappan* and Ulrich Scheler

Leibniz-Institut für Polymerforschung Dresden e. V., Hohe Straße 6, 01069 Dresden, Germany

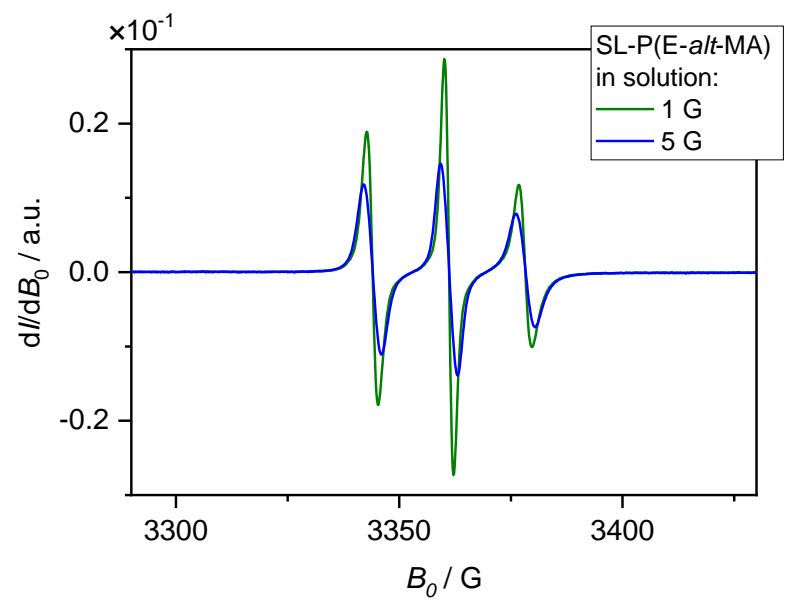

Figure S1. Experimental EPR spectra of SL-P(E-alt-MA) in solution measured with a modulation amplitude of $1 \mathrm{G}$ and 64 scans as well as $5 \mathrm{G}$ and 4 scans, respectively. The spectra are normalized to the value of the double integral.

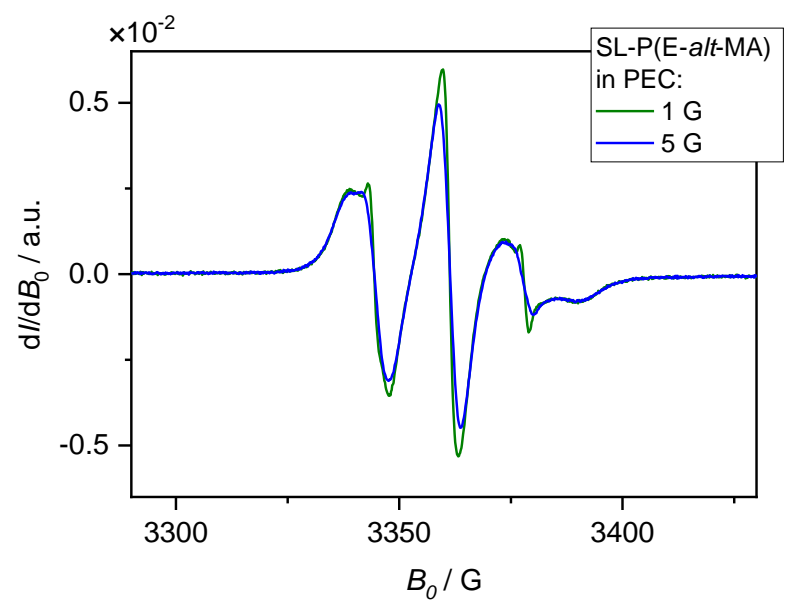

Figure S2. Experimental EPR spectra of SL-P(E-alt-MA) in PEC dispersion with PDADMAC measured with a modulation amplitude of $1 \mathrm{G}$ and 64 scans as well as $5 \mathrm{G}$ and 4 scans, respectively. The spectra are normalized to the value of the double integral. 

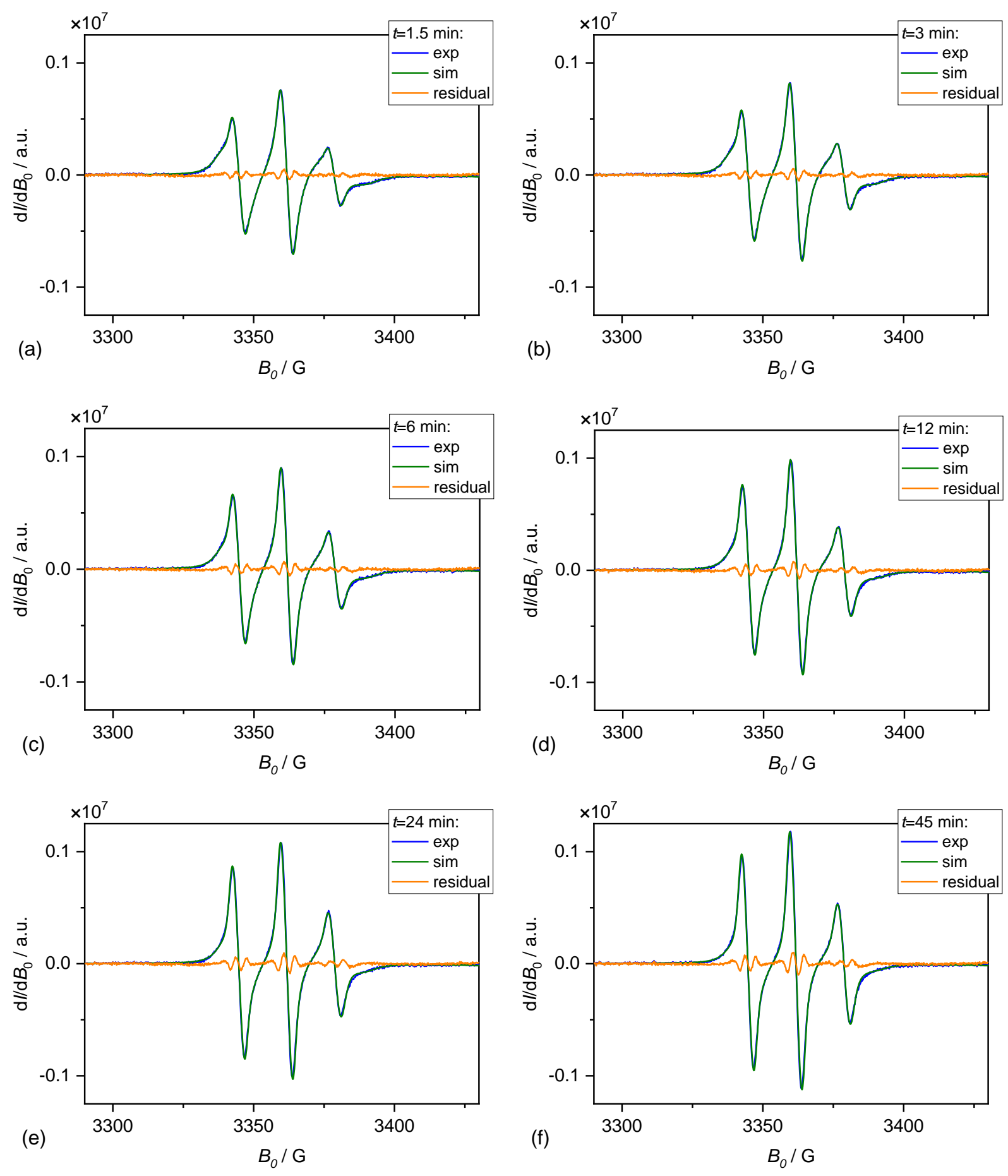

Figure S3a-f. Experimental and simulated EPR spectra of the PDADMAC/SL-P(E-alt-MA) PEC dispersion measured at different times $t$ after the addition of PSSNa. The concentration of the added $\mathrm{KCl}$ is $0.05 \mathrm{~mol} / \mathrm{L}$. 